\title{
SOCIAL NETWORKS, THEIR ROLE AND INFLUENCE ON GENERATION Y VERSUS GENERATION Z WHEN RECRUITING APPLICANTS FOR HIGHER EDUCATION INSTITUTIONS
}

\author{
Eliška Káčerková \\ Tomas Bata University in Zlin (CZECH REPUBLIC)
}

\begin{abstract}
The aim of the present study is to analyze the importance and role of social networks in the decisionmaking process of a university candidate at the moment when the generation of this target group changes. The author, together with the research goal, has been monitoring the phases and influences on the initiation and decision-making of the candidate for a long time, and the perception of online tools is changing as the generation that grew up with the Internet is emerging.

This study analyzes the differences, possibilities and barriers to the inclusion of social networks at the various stages of the impact on potential candidates as well as attitudes towards them. The basis for its processing are quantitative and qualitative surveys.

The aim of the qualitative survey was to identify specific factors regarding the behavior and habits of students in the decision-making process of choosing a higher education institution. The research was carried out in 2015 with $\mathrm{N}=12$ respondents. The quantitative survey was focused on the analysis of the decision-making process of applicants, which is regularly verified in the monitoring of attitudes. This survey was carried out in the years 2015 to 2019, providing a total of 2082 evaluated responses for this article (2015: $\mathrm{N}=714,2016: \mathrm{N}=440,2017: \mathrm{N}=99,2018: \mathrm{N}=392,2019: \mathrm{N}=437$ ). The survey's target group consisted of university candidates who were approached during an Open Day visit or in the admission process of the selected Czech higher education institution. Although it is a narrowly focused sample, it is an inspiring material that is supported by a number of secondary data sources, thus creating at least a discussion platform for university marketing staff.
\end{abstract}

The output of the paper is a model of inclusion of social networks in the communication mix of universities and a number of recommendations arising from the results.

Keywords: Higher education institution, social network, decision-making process, Generation Y, Generation Z, applicants for study.

\section{INTRODUCTION}

The differences of Generation $Y$ and Generation $Z$ in their access to sources of information from a technological standpoint and considering their ability to work with them are not too distinct. What does set these generations apart is their approach and purpose to making use of these options.

According to Shatto and Erwin (2017), Generation $Y$ was the first generation to have computers in their schools. Along with Generation Z, they are characterized by a propensity to multitask. Both generations want to have autonomy and freedom to publish and share specific content when using digital technologies. [1]

This study monitors a time period between the years 2015 and 2019, which constitutes a time when young people in the Czech Republic make a decision regarding their future university studies. These years also represent a shift between Generation $Y$ and $Z$. As evidenced by the various interpretations of the divides between generations of many scientific authors, there is no clear distinction as to where Generation $Y$ ends and the emerging Generation $Z$ begins.

According to Betz (2019), Generation Y, also known as the Millennials, are individuals born between 1980 and 1994 and Generation Z are individuals born between 1995 and 2015. [2]

Even though the distinction stated above stems from a globally recognized interpretation, there can be specific factors present in the particular countries' realities resulting in an adjustment and a slight change of the generational divide. For example, Swanzen (2018) puts Generation Y in the years 1978 to 2000 and Generation Z in the period of 1995-2012. [3] 
Jurášková et al. states that representatives from such defined generations present young people in the role of applicants for university studies. Generations $Y$ and $Z$ can be broken down by year of birth as follows: 1980-1988: older generation Y, 1989-1994: younger generation Y, 1995-1999: older generation Z, year 2000 and later: younger generation Z. [4]

According to DeVaney (2015), there are some likely differences between younger and older Millennials. The oldest Millennials entered the job market during the multiyear recession beginning in 2008, while the youngest are still obtaining their education. Millennials have responded to the recession in different ways, such as engaging in social protests, moving back in with their parents, delaying marriage, delaying buying first homes, and starting their own businesses. The Millennials are expected to become the most educated generation ever, and are also the generation with the most student debt. [5]

The youngest members of Gen $Y$ and the members of Gen $Z$ are currently entering training, higher education, or the workplace. [6]

Although opinions of experts on defining the time period of different generations show slight variations, it is evident that there is a transitional period where both generations overlap. This study focuses on understanding the role of social networks from the point of view of Gen Y and Gen Z in the decisionmaking process of choosing a university; therefore, it is necessary to consider the extent to which these generations acknowledge the digital world.

Skinner (2015) discusses the fact that Millennials have never known a world without computers, Internet access, mobile phones and other mobile devices. Their daily life is characterized by a constant effort to be online and connected to the rest of the world. They share their experiences on Facebook, read customer reviews before purchasing products and post on Twitter about the service they receive from retailers, banks and restaurants. [7]

Generation $Y$ was exposed to the digital world early in their lives. This generation and Generation $Z$ have been referred to as the "Digital Natives" given their upbringing that has been intertwined with the digital world unlike the past generations of the "Digital Immigrants". [8]

Even traditionally conservative institutions such as those of higher education have understood that there has been a change in communication style and are trying to find an effective approach to reacting to this change. The form with which potential candidates are being approached and with which their interest is being stimulated is becoming ever more digital. The following part of this article describes how this process has been reflected in a selected institution, the Faculty of Multimedia Communications at the Tomas Bata University in Zlín.

\section{METHODOLOGY}

This study is based on two mutually complementary surveys. These are a quantitative tracking survey, continuously carried out since 2015 up to the current year (2019), and a qualitative survey, carried out in 2015. Both types of research are primarily associated with the Faculty of Multimedia Communications at the Tomas Bata University in Zlín and deal with the phenomenon of the decisionmaking process of a high school student tasked with choosing a university to attend.

In the quantitative tracking survey conducted from 2015 to 2019, the question important for the purpose of this study asks the respondent where was the first time the student heard about the given university (Tomas Bata University in Zlín in this case). If the selected response was one of the options signifying different forms of either conventional or digital communication, the respondent was included in the research. If the selected response included "Don't know" or "Other", the respondent was not included in the research sample so as to avoid a distortion of the resulting values. Based on this filter, the research included a sample of $\mathrm{N}=2082$ respondents $(2015: \mathrm{N}=714,2016$ : $\mathrm{N}=440,2017: \mathrm{N}=$ 99, 2018: $\mathrm{N}=392,2019: \mathrm{N}=437$ ). The target group of the survey was always made up of university candidates who were approached during their visit to the Open Day or during admission process of the said university. Parts of the mentioned survey will serve as a data source for the analysis of the phenomenon of social media as primary sources of information for university candidates of the given university. 
In order to find out the role of social media and their influence on university candidates, the results of the qualitative survey conducted in 2015 will also be used. This period corresponds with a time when university candidates are recruited from both the youngest segment of Generation $Y$ and the oldest segment of the emerging Generation Z. The qualitative survey of a sample of 12 participants $(N=12)$ investigated the specific factors regarding the behavior and habits of students in the decision-making process of choosing a higher education institution. A total of 4 grammar school students, 2 business academy students, 4 students of a professional high school, and 2 students of a vocational school offering a final graduation exam was surveyed in a structured interview. The duration of the interview spanned from 35 to 55 minutes and a balanced ratio of both genders was maintained.

In this article, selected results of the aforementioned surveys will be presented, after which the defined hypothesis will be tested for the given area of research.

In the part of conclusions, the obtained findings are looked at in the context of the behavior of Generation $Y$ and Generation Z, who constitute the profiles of university candidates in the monitored time period. Based on the results a model of the decision-making process has been created, incorporating the impact of social networks in the different stages of this process.

\section{RESULTS}

Based on the author's long-term interest in the phenomenon of a university candidate's decisionmaking process, it has been observed that important aspects of such process include personal experience, referral of a credible individual and obtaining information from a credible source. The closer and more personal the experience with the given school is, the higher the chances of appealing to the student in a positive way from the point of view of the university. One of the most effective forms of communication is approaching high school students directly on the premises of the given university, where they can tour the school grounds, visit the university library, see the catering facilities and meet current students. [9]

Jurášková et al. suggests that the role of social networks in the decision-making process of a university candidate lies mostly in establishing a relationship. Social networks do not play a major role in the final decision of the student on whether to submit the application - their objective is rather mostly to attract them and feed them the right arguments as to why this school is better than others. The essential task is to create a community made up of students, capturing the candidate's attention to the point where they submit an application to the given university on their own. The objective of the strategy is to appeal to the candidate and to engage them in a way that they decide to visit the website, even repeatedly, and subscribe to receiving content on social media. At the right moment, the candidate is then struck by a key message, whose main task is to convince them to conversion, meaning entering their email address in a contact form or even submitting an application to the given university. [4]

\subsection{Mapping the decision-making process of a university candidate}

From the qualitative survey described above, two groups of potential students can be inferred when talking about university candidates. The first group consists of students who are set on studying a particular field of study and are deciding between various universities that offer it. The second group is comprised by students who want to study at a university but do not have a clear idea of their preferred field of study.

Another factor that can be observed is the level of independence when choosing a university. In the first group, the choice is an independent personal decision led by the candidate's intrinsic motivation. The parents of the candidate are consulted mostly regarding the financial demands of the chosen studies and the candidate's welfare. An important point of reference are the current students of the given university offering the field of study the candidate is interested in.

The second group of candidates makes their decision based on a combination of several factors. Those include their parents, classmates, high school teachers as well as the image and the attractive style of communication of the future place of study. This group considers not only the suitability of the field of study but also the presence of classmates they are familiar with, consulting their parents regarding financial conditions and the candidate's welfare, looking for references that can give them a general idea about life at the university, etc. 
The obtained findings were adapted into a diagram which sums up the decision-making process of the candidate. Despite two different groups of candidates having been determined above, the decisionmaking process stays the same in both cases. The main distinction can be found with regards to timeframe, as the first group of candidates passes through the different stages usually much earlier, given their clear choice of the future field of study. The diagram of the decision-making process comprises several consequential steps (see Figure 1).

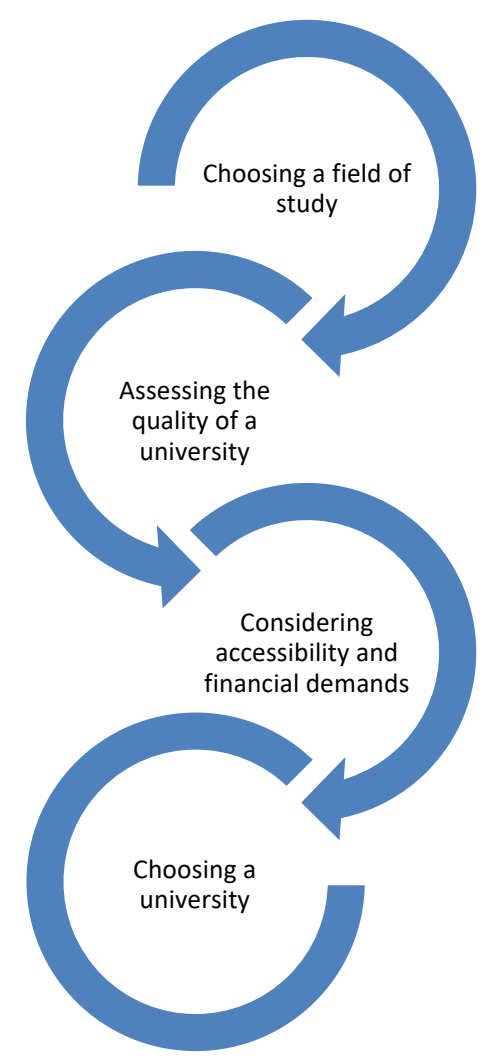

Figure 1: Diagram of the decision-making process of a university candidate (Source: own work).

\subsection{Use of social networks in university candidates}

Thanks to the data obtained from the quantitative tracking survey, this phenomenon could receive statistical evaluation. For the purposes of this publication the key question in the survey questionnaire was the one where the candidate provided where was the first time they had heard about the given higher education institution. If the response had to do with the digital world and social networks, it was marked as response $=1$. Responses which included the offline world and conventional media channels were marked as response $=0$. The research sample comprised a total of $N=2082$ respondents. The survey data were collected in the years 2015 to 2019, therefore reflecting a transitional period where there was a shift in the candidates' belonging to Generation $Y$ or Generation Z. The second variable in the table represents the year in which the candidate participated in the survey, i.e. 2015, 2016, 2017, 2018, and 2019. Table 1 provides a complete statistical evaluation of the collected data.

Table 1: Test on social networks in the studied years (Source: own work).

\begin{tabular}{l|c|c|c|c|c|c|c|c|c|c|c|c|c}
\hline \hline & vars & $n$ & mean & sd & median & trimmed & mad & min & max & range & skew & kurtosis & se \\
\hline Response & 1 & 2082 & 0.08 & 0.27 & 0 & 0 & 0 & 0 & 1 & 1 & 3.05 & 7.33 & 0.01 \\
\hline Year & 2 & 2082 & 2016.71 & 1.59 & 2016 & 2016.64 & 1.48 & 2015 & 2019 & 4 & 0.28 & -1.55 & 0.03 \\
\hline \hline
\end{tabular}


Strictly theoretically speaking, it can be said that an average of $8 \%$ of respondents used social networks. Emphasis was put on the year of completing the questionnaire when setting up the hypothesis, as the period between 2015 and 2019 marked the transition from Generation $Y$ to Generation Z. Upon this reflection, the null hypothesis then states:

$\mathrm{H}_{0}$ : The year of completing the survey, or belonging to a certain generation, has no statistically significant effect on the use of social networks as a source of information in the decision-making process of university candidates.

In order to assess this relationship, a chi-squared test of independence was performed (see Table 2).

Table 2: Chi-squared test of independence.

\begin{tabular}{c|c|c}
\hline \hline & 0 & 1 \\
\hline 2015 & 650 & 64 \\
\hline 2016 & 425 & 15 \\
\hline 2017 & 92 & 7 \\
\hline 2018 & 358 & 34 \\
\hline 2019 & 387 & 50 \\
\hline \hline
\end{tabular}

(Source: own work)

Subsequently, Pearson's chi-squared test was carried out. Its results (X-squared $=20.43, \mathrm{df}=4, \mathrm{p}$ value $=0.0004107$ ) show, due to the $p$-value being less than 0.05 , that there is sufficient proof in order to reject the null hypothesis of independent variables. We can therefore assume that they year of completing the questionnaire (or rather the year of birth determining the belonging to a certain generation) and the use of social networks are two variables with a statistically significant dependence.

The next step was to set up a hypothesis that tested whether the dependence is a linear relationship.

$\mathrm{H}_{0}$ : There is no linear relationship between the year of completing the survey and the use of social networks.

Kendall's tau coefficient was used in order to test this dependence. The results $(z=1.4812, p$-value $=$ 0.1386 , alternative hypothesis: true tau is not equal to 0 , sample estimates: tau $=0.02947102)$ show that the $p$-value is greater than the 0.05 value and therefore there is insufficient proof for the rejection of the null hypothesis of linear regression assuming a non-normal distribution of data. This means that the number of candidates who use social networks as a source of information on universities having an effect on their choice of studies does not increase as the years progress and is rather constant. The particular portions of social network users in this area are expressed by values: year $2015-8 \%$, $2016-3 \%, 2017-7 \%, 2018-8 \%$ a $2019-11 \%$. With the exception of 2016 , where a major decrease can be observed, there is a certain increasing trend, which cannot however be statistically proven at this point. Given the current trends in the society, we can presume that the number of social network users in the context of the phenomenon of choosing a university will only increase over time.

\section{CONCLUSIONS}

Both conducted surveys have provided information and conclusions leading to a synthesis of results. Based on the diagram created in Section 3.1 and the hypotheses tested in Section 3.2, a model of a candidate's decision-making process has been created, providing recommendations concerning opportunities for communication on social media. While the left side features the various stages of the decision-making process, the right side proposes different topics for communication on social networks (Figure 2). 


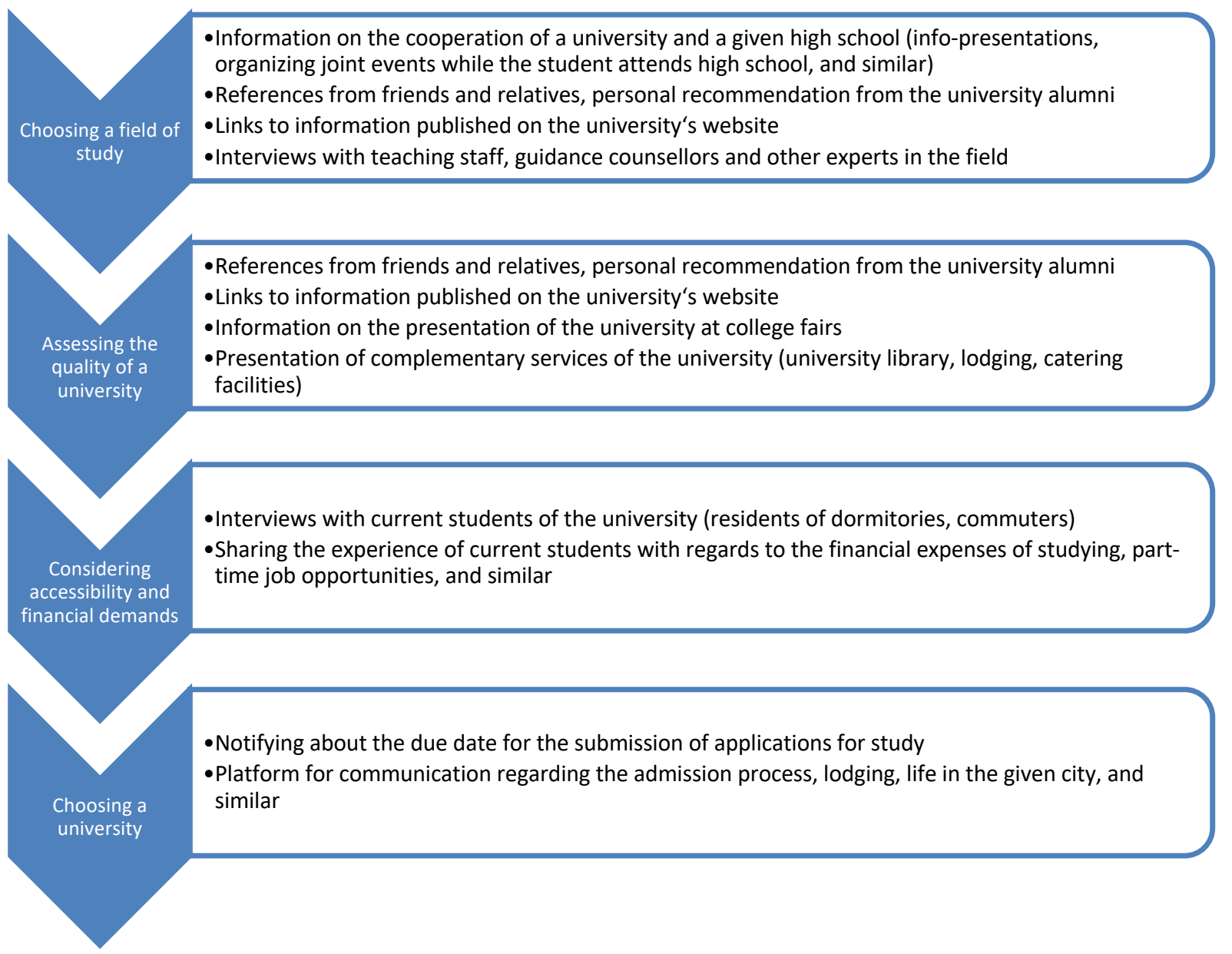

Figure 2: Opportunities for communication on social networks in the decision-making process of a university candidate (Source: own work).

Even though social media use as the first contact of a university candidate in the observed time period was at $8 \%$, an increasing significance of this form of communication can be expected due to the characteristic features of the emerging Generation Z. Hence, several options have been drawn up, which can serve as a guideline when creating content that can be effectively communicated on social media. These recommendations were based on the answers of the participants of the qualitative survey described above.

When it comes to the major differences between Gen $Y$ and Gen $Z$ with regards to social media, the conclusion is clear: Generation $Y$ did not deem information obtained on social networks as significant when choosing a university; older members of Generation $Y$ lacked this type of information completely. As time progresses, higher education institutions are learning to make use of the informative and influential potential of social media, creating interesting content, with which they seek to primarily attract the attention of candidates. Due to the increasing trend of Generation Z following the content communicated on social media by universities, we can expect that in the future, even information of a more essential nature, currently mostly published through conventional communication channels, will make its way to this communication channel.

\section{ACKNOWLEDGEMENTS}

This article was created on the basis of support from the Competition for the Promotion of Excellence in Research and Creative Projects entitled Support of Creative Activities of the Institute of Marketing Communications of the Faculty of Multimedia Communications of Tomas Bata University in Zlín in excellent directions n. 090/2019/TVČ. 


\section{REFERENCES}

[1] B. Shatto \& K. Erwin. "Teaching Millennials and Generation Z: Bridging the Generational Divide," Creative Nursing, vol. 23, no. 1, pp. 24-28, 2017.

[2] C. L. Betz. "Generations X, Y, and Z," Journal of Pediatric Nursing, vol. 44, no. January February, pp. A7 - A8, 2019.

[3] R. Swanzen. "Facing the Generation Chasm: The Parenting and Teaching of Generations $Y$ and Z," International Journal of Child, Youth and Family Studies, vol. 9, no. 2, pp. 125 - 150, 2018.

[4] O. Jurášková, M. Juříková, J. Kocourek \& R. Čočková. "Differences in the Expected Contribution of Higher Education in the Millennials Generation and the Generation Z," ICERI 2016 Proceedings, 2016. Retrieved from https://library.iated.org/view/JURASKOVA2016DIF

[5] S. A. DeVaney. "Understanding the Millennial Generation," Journal of Financial Service Professionals, vol. 69, no. 6, pp. 11-14, 2015.

[6] R. Swanzen. "Facing the Generation Chasm: The Parenting and Teaching of Generations $Y$ and Z," International Journal of Child, Youth and Family Studies, vol. 9, no. 2, pp. 125 - 150, 2018.

[7] R. Skinner. "How Millennials are Fuelling the Need for Technology Innovation in Insurance," National Underwriter Life and Health, vol. 119, no. 3, pp. 31, 2015.

[8] M. Prensky. "Digital Natives, Digital Immigrants - Part 1," On the Horizon, vol. 9, no. 5, pp. 1-6, 2001.

[9] E. Káčerková. "Preferences of Communication Tools in Choice of High School," Marketing Identity, vol. 6, no. 1, pp. $85-92,2018$. 